\title{
Microplastics and sorbed contaminants - Trophic exposure in fish sensitive early life stages
}

\author{
Cousin Xavier 1, 2, 3, ${ }^{*}$, Batel Annika ${ }^{4}$, Bringer Arno ${ }^{1}$, Hess Sebastian ${ }^{5}$, Bégout Marie-Laure ${ }^{1,2}$, \\ Braunbeck Thomas ${ }^{5}$
}

${ }^{1}$ Laboratoire Ressources Halieutiques, IFREMER, Place Gaby Coll, L'Houmeau, France

2 MARBEC, Univ. Montpellier, CNRS, IFREMER, IRD Palavas-les-Flots, France

3 Univ. Paris-Saclay, AgroParisTech, INRAE, GABI, Jouy-en-Josas, France

${ }^{4}$ Aquatic Ecology and Toxicology, Centre for Organismal Studies, University of Heidelberg, Heidelberg, Germany

*Corresponding author : Xavier Cousin, email address : xavier.cousin@ifremer.fr

\begin{abstract}
:
The present study evaluated very small microplastic particle (MPs) transfer to zebrafish and marine medaka larvae via prey experimentally exposed to MPs from the onset of feeding. Larvae were fed Paramecium or Artemia nauplii loaded with fluorescent 1-5 or 10-20 $\mu \mathrm{m}$ MP. Pollutant accumulation was analyzed by optically tracking of benzo [a]pyrene $(\mathrm{BaP})$ and recording cyp1a transcription. Paramecium transferred 1-5 $\mu \mathrm{m}$ particles only, whereas Artemia efficiently transferred both MPs. Although zebrafish and medaka larvae fed from the onset of active food intake (2-3 dph, respectively) on Paramecium and from days 6-7 post-hatch on Artemia nauplii, neither MP accumulation nor translocation to tissues was detected. MP egestion started within few hours after ingestion. Cyp1a induction and fluorescent analyses proved $\mathrm{BaP}$ bioavailability after transfer via Paramecium and Artemia. Unicellular or plankton organisms ingest contaminants via MPS and transfer effectively these to sensitive early life-stages of vertebrates, giving rise to whole-life exposure.
\end{abstract}

\section{Graphical abstract}
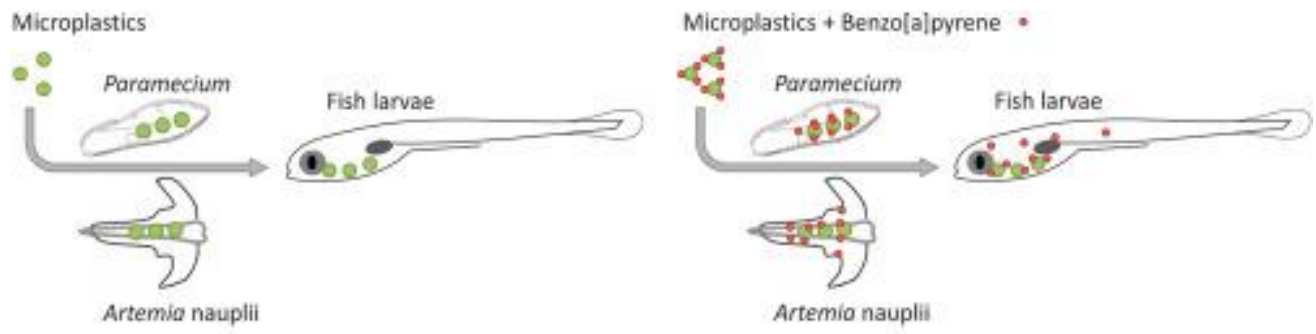

Prey as Paramecium and Artemia nauplii efficiently transfer very small microplastics and associated benzo[a]pyrene to zebrafish and marine medaka larvae exposing sensitive early life stages of fish 


\section{Highlights}

- Microplastics are readily ingested by unicellular or planktonic organisms. Microplastics are efficiently delivered to fish larvae from these organisms. Benzo [a]pyrene sorbed on microplastics is transferred from prey to fish larvae.

Keywords : Trophic transfer, microplastics, fish, larvae, benzo[a]pyrene, Paramecium, Arte mia, zebrafish, marine medaka 
Today, microplastic particles (MPs) are found ubiquitously in any water body (Browne et al., 2011; Eerkes-Medrano et al., 2015; Eriksen et al., 2014; Van Cauwenberghe et al., 2015). Along with increasing occurrence in the environment, detection rates of MPs in marine biota have been well documented especially in zooplankton and fish (Cole et al., 2013; Desforges et al., 2015; Hermsen et al., 2017; Rummel et al., 2016; Steer et al., 2017; Watts et al., 2015). However, eventual effects by MPs in marine and freshwater organisms and their potential impact on ecosystems have remained a matter of debate for more than a decade (Heinrich et al., 2020; Koelmans et al., 2016; Lohmann, 2017; Thompson et al., 2004; Wright et al., 2013).

Ingestion of MPs has been demonstrated across a wide range of phyla (e.g. zooplankton, mollusks, marine worms, fish), and their adverse effects might be attributed to different processes including the lack of egestion (occlusion effects) or the induction of false satiation after ingestion of MPs and the devoid of nutritional value as reviewed in Eerkes-Medrano et al. (EerkesMedrano et al., 2015). In some cases ingestion of virgin MPs induced no or limited toxicity (Beiras et al., 2018; Cormier et al., 2019; Le Bihanic et al., 2020; Mazurais et al., 2015) while in other cases they have been shown to induce inflammatory processes and physiological stress responses (Jovanovic, 2017; Karami et al., 2017; von Moos et al., 2012; Wright et al., 2013), which may be the consequence of physical or chemical insults (due to additives for the latter). In a review, (Hermabessiere et al., 2017) summarize reports on effective transfer of plastic additives to marine organisms including phthalates, nonylphenol, bisphenol $\mathrm{A}$ and brominated flame retardants.

Beyond such intrinsic toxicity, another potential threat attributed to MPs is due to their physicochemical properties, which favor the adsorption of hydrophobic chemicals on their surface. As a consequence, hydrophobic compounds present in aquatic environments accumulate on MPs, as shown for a wide variety of substances including polychlorinated biphenyls (PCBs), polycyclic aromatic hydrocarbons (PAHs) and metals (Alimba and Faggio, 2019; Ashton et al., 2010; Bakir et al., 2012; Endo et al., 2005; Fisner et al., 2013; Mato et al., 2001; Ogata et al., 2009; Rios et al., 2007; Strungaru et al., 2019; Velzeboer et al., 2014). Yet, the importance of MPs as vectors for adsorbed contaminants has been under discussion and - according to modeling approaches - has been assumed not to be major (Bakir et al., 2016; Heinrich et al., 2020; Koelmans et al., 2016; Lohmann, 2017). In part, experiments agree with such modeling by documenting the absence or a minor role for MPs as vectors for pollutants (Besseling et al., 2017; Devriese et al., 2017). In contrast, other experimental studies demonstrated that contaminants adsorbed on MPs can effectively be transferred to organisms (Batel et al., 2016; Gassel and Rochman, 2019; Rochman et al., 2013; Scopetani et al., 2018; Teuten et al., 2009; van der Hal et al., 2020; Wardrop et al., 2016) and can elicit molecular responses (Avio et al., 2015; Rochman et al., 2013; Sleight et al., 2017). Most likely, the potential role of MPs as vectors for pollutants depends on the physicochemical properties of the pollutants as revealed by both experimental approaches and field sampling (Diepens and Koelmans, 2018; Gassel and Rochman, 2019). 
In the marine environment, coastal areas are considered of major importance, as they represent nurseries for many fish species (Beck et al., 2001). Simultaneously, these areas are close litter sources and, thus, characterized by relatively high concentrations of MPs and chemical pollutants (Browne et al., 2011; Guzzetti et al., 2018; Hermsen et al., 2017). The increase in MPs and MPs ingested in larvae observed in coastal slick supports this hypothesis (Gove et al., 2019). As a consequence, fish early development and larval stages may be speculated to be affected in different or stronger manners by MPs and associated hazardous chemicals than adult organisms. Fish larvae mainly feed on diverse zooplankton species, which have been shown to ingest MPs (Cole et al., 2013; Desforges et al., 2015). Zooplankton may then act as a funnel delivering high amounts of MPs to fish larvae; relative to body weight, amounts of pollutants may be larger than in adult fish. The contribution of zooplankton to the transfer of MPs to fish larvae might, therefore, be a major issue for fish stock sustainability, but is largely unknown so far (Au et al., 2017). Thus, even if exposure to contaminants through MP ingestion may theoretically not be a major source for the uptake of contaminants, trophic transfer via food webs might still represent an important route for the transfer of MP and associated contaminants to ecologically sensitive life-stages of aquatic organisms. Especially early exposure to elevated amounts of MPs might potentially have larger impact on fish early life-stages than on adult fish.

For these reasons, the present study was designed to evaluate how very small MPs and associated contaminants transfer via prey exposed to MPs and how they affect early life-stages of fish. In order to avoid possible species-specific findings, we used two evolutionary distant model fish species, the freshwater zebrafish (Danio rerio) and the marine medaka (Oryzias melastigma) both being frequently used for ecotoxicology studies. Similarly, as prey, we used two unrelated organisms, Paramecium and Artemia, as two plankton-like models of contrasting sizes. Following the approach by Batel et al. (2016) in adult fish, we analyzed (1) the trophic transfer of MPs to larvae of zebrafish and of the marine medaka via Paramecium and Artemia, (2) the quantitative and qualitative transfer of MPs and associated chemicals, and finally (3) the bioavailability of chemicals transferred from MPs to fish larvae.

\section{Materials and Methods}

\section{Fish husbandry}

Adult zebrafish (Danio rerio) aged 12 months were obtained from the breeding and maintenance facilities of the Aquatic Ecology and Toxicology Group at the Center for Organismal Studies Heidelberg (licensed by regional animal welfare authorities under 35-9185.64/BH Braunbeck). Temperature was maintained at $25.0 \pm 1.0{ }^{\circ} \mathrm{C}$, and fish were kept under a constant artificial dark/light cycle of $8 / 16 \mathrm{~h}$. Constant filtering plus permanent flow-through conditions guaranteed that ammonia, nitrite, and nitrate concentrations were kept below detection limits $(5,1$ and $140 \mathrm{mg} / \mathrm{L}$, respectively). Fish were fed commercially available artificial diets (TetraMin ${ }^{\mathrm{TM}}$ flakes; Tetra, Melle, Germany) twice daily ad libitum, supplemented with Artemia nauplii of appropriate size (Instar II, 2 pipettes per 10 fish; (Lim et al., 2003) obtained 
from uncontaminated sources. Zebrafish eggs were obtained according to Lammer et al. (2009).

Marine medaka (Oryzias melastigma) brood stocks are routinely maintained in the Laboratoire Ressources Halieutiques, Ifremer (facility authorization A171901; project authorization APAFIS\#10883) from a stock obtained as embryos in 2007 from the laboratory of Dr. Doris Au (State Key Laboratory in Marine Pollution, City University of Hong Kong, China). Juveniles and adult fish were reared in recirculating systems in water at $25 \%$ salinity in an isothermal room at $26 \pm 1^{\circ} \mathrm{C}$ with a $14 / 10 \mathrm{~h}$ light/dark photoperiod. Fish were fed twice a day with food pellets of various size depending on their age (Special Diets Services, Dietex France, Argenteuil, France) with an additional feeding at noon with freshly hatched brine shrimp (Artemia) nauplii (Ocean Nutrition Europe, Essen, Belgium).

Eggs were collected by siphoning tanks bottom within 4 hours after light onset and quickly cleaned. In order to remove chorionic projections, eggs were rolled on sandpaper (p.2000) as described for Japanese medaka (Porazinski et al., 2010), extensively rinsed in order to remove debris and finally transferred to Petri dishes filled with artificial $20 \mu \mathrm{m}$-filtered synthetic artificial seawater (Instant Ocean; salinity $25 \%$ o, $\mathrm{pH}=8.0$ ) containing methylene blue.

\section{Chemicals}

Unless stated otherwise, all chemicals were purchased from Sigma-Aldrich (Deisenhofen, Germany, or St. Quentin Fallavier, France) at the highest purity available.

\section{Microplastics (MPs) and benzo[a]pyrene (BaP) spiking}

Green fluorescent microspheres of two sizes were purchased from Cospheric (Santa Barbara, CA, USA): (1) proprietary plastic microspheres with a size range of 1 - $5 \mu \mathrm{m}$ range and a density of $1.3 \mathrm{~g} / \mathrm{cc}$ (catalogue code: FMG-1.3 1-5 $\mu \mathrm{m}$; later referred to as MP5), and (2) polyethylene plastic microspheres with a size range of $10-20 \mu \mathrm{m}$ and a density of $1.00 \mathrm{~g} / \mathrm{cc}$ (catalogue code: UVPMS-BG-1.00 10-20 $\mu$ m; later referred to as MP20). Characterization of MPs polymers was performed as described in Supporting information (S1).

MP spiking was performed according to previously published protocols (Batel et al., 2018; Batel et al., 2016). BaP from stock solution in acetone (maximum amount used $100 \mu \mathrm{l}$ ) was added to double-distillated water to a total volume of $10 \mathrm{ml}$ in a $50 \mathrm{ml}$ glass bottle. Approximately $1.2 \times 10^{6}$ particles, corresponding to $0.5 \mathrm{mg}$ of MP5 or $2.5 \mathrm{mg}$ of MP20 were added and incubated overnight on a shaker (Rocky 1010; Fröbel, Lindau, Germany). After spiking, solutions were filtered over sterile $0.45 \mu \mathrm{m}$ nitrocellulose filters (TOP CA Sterile Syringe Filter, Berrytec, Grünwald, Germany), washed three times with double-distilled water and finally recovered in $10 \mathrm{ml}$ of double-distilled water. Nominal $\mathrm{BaP}$ concentrations used for spiking were 10, 100 and $300 \mu \mathrm{M}$; spiked MPs will later be called MP-BaP10, MP-BaP100 or MP-BaP300. In previous studies, chemical analyses had shown that over $90 \%$ of BaP bound 
to MPs and that there were no solubility problems (Batel et al., 2016). An additional desorption control was used to analyze the potential desorption of BaP from spiked MPs after $24 \mathrm{~h}$ incubation in clean water and to simulate the potential direct transfer of desorbed BaP via the water column. The desorption control (DC) was prepared by incubating the spiked, washed and filtered MPs for $24 \mathrm{~h}$ in double-distilled water under continuous agitation. MPs were then filtered out, and larvae were exposed to the residual water and BaP potentially re-dissolved.

For definition of exposure groups, see Table 1.

Table 1: Definition of exposure group codes used in the present study

\begin{tabular}{lccc}
\hline Exposure group & Live prey & MPs & Benzo[a]pyrene (BaP) \\
\hline MP5 & - & MP 1-5 $\mu \mathrm{m}$ & - \\
MP20 & - & MP 10- 20 $\mu \mathrm{m}$ & - \\
& & & \\
Par-MP5 & Paramecium & MP5 & - \\
Par-MP20 & Paramecium & MP20 & - \\
Par-MP5-BaP10 & Paramecium & MP5 & $10 \mu \mathrm{M}$ \\
Par-MP20-BaP10 & Paramecium & MP20 & $10 \mu \mathrm{M}$ \\
& & & - \\
Art-MP5 & Artemia & MP5 & - \\
Art-MP20 & Artemia & MP20 & $100 \mu \mathrm{M}$ \\
Art-MP5-BaP100 & Artemia & MP5 & $300 \mu \mathrm{M}$ \\
Art-MP5-BaP300 & Artemia & MP5 & - \\
& & & $100 \mathrm{nM}$ \\
NC (negative control) & - & - & BaP re-solution \\
PC (positive control: & - & - & control (see text) \\
waterborne BaP) & - & & \\
DC (desorption control) & & &
\end{tabular}

Trophic transfer from Paramecium to fish larvae

\section{MP uptake by Paramecium}

Paramecia (Paramecium spec.) were obtained from a permanent culture of the Aquatic Ecology and Toxicology Group at the Center for Organismal Studies (University of Heidelberg, Germany). The culture was kept in glass bottles darkened with aluminum foil and filled with artificial seawater $\left(1.5 \mathrm{~g}\right.$ Artemia salt $\left[9.52 \mathrm{~g} / \mathrm{L} \mathrm{Na}^{+}, 0.71 \mathrm{mg} / \mathrm{L} \mathrm{Mg}^{2+}, 0.24 \mathrm{~g} / \mathrm{L} \mathrm{Ca}^{2+}, 0.22 \mathrm{~K}^{+}\right.$, $11.0 \mathrm{~g} / \mathrm{L} \mathrm{Cl}^{-}, 1.54 \mathrm{~g} / \mathrm{L} \mathrm{SO}_{4}{ }^{2-}$ per $5 \mathrm{~L}$ distilled water]; Preis Aquaristik, Bayerfeld-Steckweiler, Germany)). Paramecium was fed with 5 cooked wheat grains per L (50 grains cooked in 50 $\mathrm{ml}$ distilled water for $10 \mathrm{~min}$ at $300{ }^{\circ} \mathrm{C}$ ). Paramecium cultures were split every two weeks in order to prevent a decrease in population density. 
For the monitoring of MP ingestion, approx. $1.2 \times 10^{6} \mathrm{MP}$ particles (about 0.5 or $2.5 \mathrm{mg}$ of MP5 or MP20, respectively) were mixed in $9 \mathrm{ml}$ of Paramecium rearing medium in glass Petri dishes. For better mixing of Paramecium and MPs, Petri dishes were incubated on a REAX 3 hinged plate (Heidolph, Schwabach, Germany). After 1, 3 and $5 \mathrm{~h}$ incubation, $1.5 \mathrm{ml}$ of the solution were transferred to a $2 \mathrm{ml}$ tube. Paramecium rearing media were filtered through a $100 \mu \mathrm{m}$ filter (EASY strainer, Greiner, Frickenhausen, Germany) into new tubes and washed with $1 \mathrm{ml}$ artificial sea water. Paramecium passed the filter, whereas MPs attached to the filter or to the plastic walls of the tubes due to hydrophobic interactions. The tubes were then spun in a table centrifuge (Mini centrifuge, National Labnet, Woodbridge, USA) for $2 \times 10 \mathrm{sec}$. Remaining MP5 with higher density than water sedimented at the bottom or along the wall of the vessel, whereas MP20 particles with lower density than water floated at the water surface. Separated Paramecium were sampled from the layers in-between and later called Par-MP.

Paramecium were transferred to confocal dishes, and MP uptake was tracked with a Nikon Eclipse 90i epifluorescence microscope (Nikon, Düsseldorf, Germany). For photography, Paramecium were immobilized with a saturated EDTA $(5 \mathrm{~g} / 15 \mathrm{ml})$ solution.

\section{MPs transfer from Paramecium to fish larvae}

The transfer of MPs from Paramecium to zebrafish larvae was tested at different ages of the larvae (96 - 192 hours post-fertilization, hpf) and for different feeding durations (1 - $6 \mathrm{~h}$, Table 2). One zebrafish larva was transferred to each well of a 24-well plate (TPB, Trasadingen, Switzerland) in $1.5 \mathrm{ml} \mathrm{ISO} 7346 / 3$ water $(64.7 \mathrm{mg} / \mathrm{L} \mathrm{NaHCO} 3,5.7 \mathrm{mg} / \mathrm{L} \mathrm{KCl}, 294.0 \mathrm{mg} / \mathrm{L}$ $\mathrm{CaCl}_{2} \times 2 \mathrm{H}_{2} \mathrm{O}, 123.3 \mathrm{mg} / \mathrm{L} \mathrm{MgSO}_{4}$; (ISO, 1996)). Paramecium were fed MPs for $1 \mathrm{~h}$ and separated from particles in solution as described above. $500 \mu \mathrm{l}$ of Par-MP solution were added to each well to reach approximately 30 Paramecium per fish larva. The 24 -well plates were sealed (Excel scientific, SealPlate, USA), and zebrafish larvae were incubated at $26{ }^{\circ} \mathrm{C}$ for 1 $6 \mathrm{~h}$ with Par-MP. After incubation, the medium was carefully removed from the larvae, which were then euthanized by adding $1 \mathrm{ml}$ tricaine ( $400 \mathrm{mg} / \mathrm{L}$ ethyl-4-aminobenzoate). After transfer to confocal dishes, the uptake of MPs via Paramecium was analyzed with a Nikon Eclipse 90i epifluorescence microscope.

Marine medaka exposure to Par-MP followed the same protocol with the exception that exposure started 1-2 days post-hatch corresponding to 11-12 days post-fertilization (dpf).

\section{MP transfer from Artemia to fish larvae}

\section{MP uptake by Artemia nauplii}

Artemia nauplii were exposed to MPs as previously described (Batel et al., 2016). In brief, Artemia cysts were incubated in seawater at $26{ }^{\circ} \mathrm{C}$ under constant aeration. After $48 \mathrm{~h}$ incubation, Instar II stage nauplii (Lim et al., 2003) were collected and counted after dilution under a dissecting microscope. This nauplii stage has been chosen as it is the first Artemia stage in- 
gesting particles being still small enough to match larvae mouth size. Approx. 10.000 nauplii were incubated further in $30 \mathrm{ml}$ of seawater with approx. $1.2 \times 10^{6}$ MP5 or MP20 particles and kept under constant aeration for oxygen supply and agitation of Artemia nauplii and MPs. Artemia nauplii were then filtered using a $100 \mu \mathrm{m}$ mesh and rinsed thoroughly. In the further text, Artemia nauplii incubated with MPs will be referred to as Art-MP.

For 2 days of exposure, freshly harvested Artemia nauplii were distributed to zebrafish larvae twice daily. For monitoring of MPs elimination kinetics, larvae were fed another 2 days with non-loaded Artemia nauplii prepared as described above. Every evening, $1 \mathrm{~h}$ after the last feeding of the day, some larvae were collected and euthanized using an overdose of benzocaine solution $(500 \mathrm{mg} / \mathrm{L})$ and observed under an Olympus BX41 epifluorescence microscope (Olympus, Rungis, France; magnification 40×, light source: X-Cite EXFO with GFP filter). Fluorescent larvae were counted to calculate the proportion of larvae having ingested MPloaded Artemia and imaged using DMK 31AU03 camera and IC Capture software (The Imaging Sources, Elvitec, Pertuis, France). Fluorescence was then quantified using ImageJ (Schneider et al., 2012) with correction for background fluorescence. A total of 20 larvae for each exposure group were monitored in triplicate.

\section{Trophic transfer of MP-associated benzo[a]pyrene (BaP) and cypla induction in fish larvae}

\section{Fish larvae exposure}

The transfer of $\mathrm{BaP}$ from microplastics through planktonic organisms to fish larvae was evaluated in zebrafish via Paramecium and in marine medaka via Artemia nauplii to show the potential of MP trophic transfer from the very first feeding of the fish larvae. In the case of zebrafish, 10 individuals of $7 \mathrm{~d}$ old larvae per exposure group were analyzed in three independent replicates. Larvae of the negative control (NC) were incubated in artificial water; positive controls (PC) contained $100 \mathrm{nM}$ waterborne $\mathrm{BaP}$, with the wells pre-incubated overnight with the $\mathrm{BaP}$ solution for of the plastic well walls. MPs were spiked, and Paramecium were incubated with spiked MPs as described above. Six ml Paramecium rearing medium were mixed with $2 \mathrm{ml}$ of the MPs loaded with BaP; except for negative and positive controls, the other test groups were also diluted 1:3 with ISO water. For this end, $500 \mu 1$ of the test solutions were added to the wells (final volume $2 \mathrm{ml}$ ), and larvae were incubated for 3 hours at $26 \pm 1{ }^{\circ} \mathrm{C}$. After incubation, the medium was discarded, and the larvae were euthanized as described above and used for either fluorescence tracking or cypla analysis.

In the case of marine medaka, $17 \mathrm{~d}$ old larvae were used. MP5-BaP and Art-MP5-BaP were prepared as described above. Likewise, larval exposure was performed as described above for 2 days ( 4 meals), and larvae were collected 3 hours after the last meal and euthanized using an overdose of benzocaine solution $(500 \mathrm{mg} / \mathrm{L})$, rinsed thoroughly in water and stored for cypla transcription analyses. A total of 6 pools of 10 larvae were collected from three exposure replicates. 
The subsequent evaluation of the fluorescence signal of the $\mathrm{BaP}$ required a positioning of the larvae as identical as possible. Within a drop of $0.1 \%$ low melting agarose $\left(26 \pm 2{ }^{\circ} \mathrm{C}\right.$; MatTek, Ashland, USA), larvae were positioned on their left sides and fixed by gelling of the low melting agarose $(100 \mathrm{mg} / 10 \mathrm{ml} 0.016 \%$ tricaine $)$. Micrographs were taken in the DAPI fluorescence channel (340 - $380 \mathrm{~nm}$ excitation, 435 - $485 \mathrm{~nm}$ emission) of a Nikon Eclipse 90i epifluorescence microscope (Nikon, Tokyo, Japan) with an exposure time of 2 seconds.

\section{Cyp1a gene transcription analysis}

To evaluate bioavailability of BaP, we monitored transcription of cypla which is known to be induced in vertebrates, by a wide range of chemicals including $\mathrm{BaP}$ ( $\mathrm{Ma}$ and $\mathrm{Lu}, 2007$ ). For cypla gene transcription analyses, larvae were washed three times in RNAse-free water immediately after sampling and stored in RNALater at $-20^{\circ} \mathrm{C}$ until further processing. Prior to RNA extraction, RNALater was removed, and embryos were immersed in lysis buffer (Quiagen, Les Ulis, France) before disruption in a Beadblaster (Benchmark Scientific, Dutscher, France). The total RNA extraction followed the protocols of the RNeasy Plus Universal Mini Kit (Quiagen). Quality and quantity of the extracts were checked using electrophoresis migration and spectrophotometric dosing. Subsequently, cDNA was synthesized from $2 \mu \mathrm{g}$ of the total RNA, using $2 \mu$ l of Superscript III Reverse Transcriptase (Invitrogen, Fisher Scientific, Illkirch, France) according to the manufacturer's protocol in a final volume of $21 \mu \mathrm{l}$. Prior to analysis, all cDNA was diluted 5 times in Milli-Q water. The qPCR experiments were run in a final volume of $20 \mu \mathrm{l}$, including an optimized primer concentration range between 300 and $600 \mathrm{nM}$ (Eurofins Genomics, Ebersberg, Germany) and 2X Fast SYBR Green Master Mix (Applied Biosystems, Fisher Scientific, Illkirch, France). Technical triplicates were run for each biological replicate. The analysis software Relative Expression Software Tool (REST; (Pfaffl, 2001; Pfaffl et al., 2002)) automatically calculated fold changes in transcription relative to negative controls (NC; cf. Table 1) using the 3 most stable references genes between all groups, and combined into an index via the free access BestKeeper software (Pfaffl et al., 2004). Reference genes were $g 6 p d$, $a c t b 1$ and $b 2 m$ for zebrafish and $g 6 p d$, $a c t b 1$ and 18 s for medaka.

\section{Results}

Trophic transfer of microplastic particles from Paramecium to zebrafish and medaka larvae

After 1, 3 and $5 \mathrm{~h}$ incubation to microplastics, Paramecium was analyzed for MP uptake. In general, MP5 particles were taken up more efficiently than MP20: After $1 \mathrm{~h}$ incubation, all Paramecium individuals contained high numbers of MP5 particles within nutritive vacuoles (Fig. 1A), which remained constant after 3 and $5 \mathrm{~h}$ of incubation. In contrast, only a small amount of MP20 particles were visible inside about $10 \%$ of the Paramecium individuals (Fig. 1B). Although with longer incubation time the number of Paramecium with ingested MP20 
increased, the overall number of microplastic particles absorbed remained low, if compared to MP5. Because of the small number of MP20 particles within Paramecium, only very few of the bigger MP20 particles were observed in the intestinal tract of zebrafish larvae after feeding Par-MP20, whereas the signal was far stronger when feeding Par-MP5 (Figs. 1C-D). A similar experiment was performed with marine medaka confirming efficient transfer of MP5 through Paramecium (Fig. 1E).

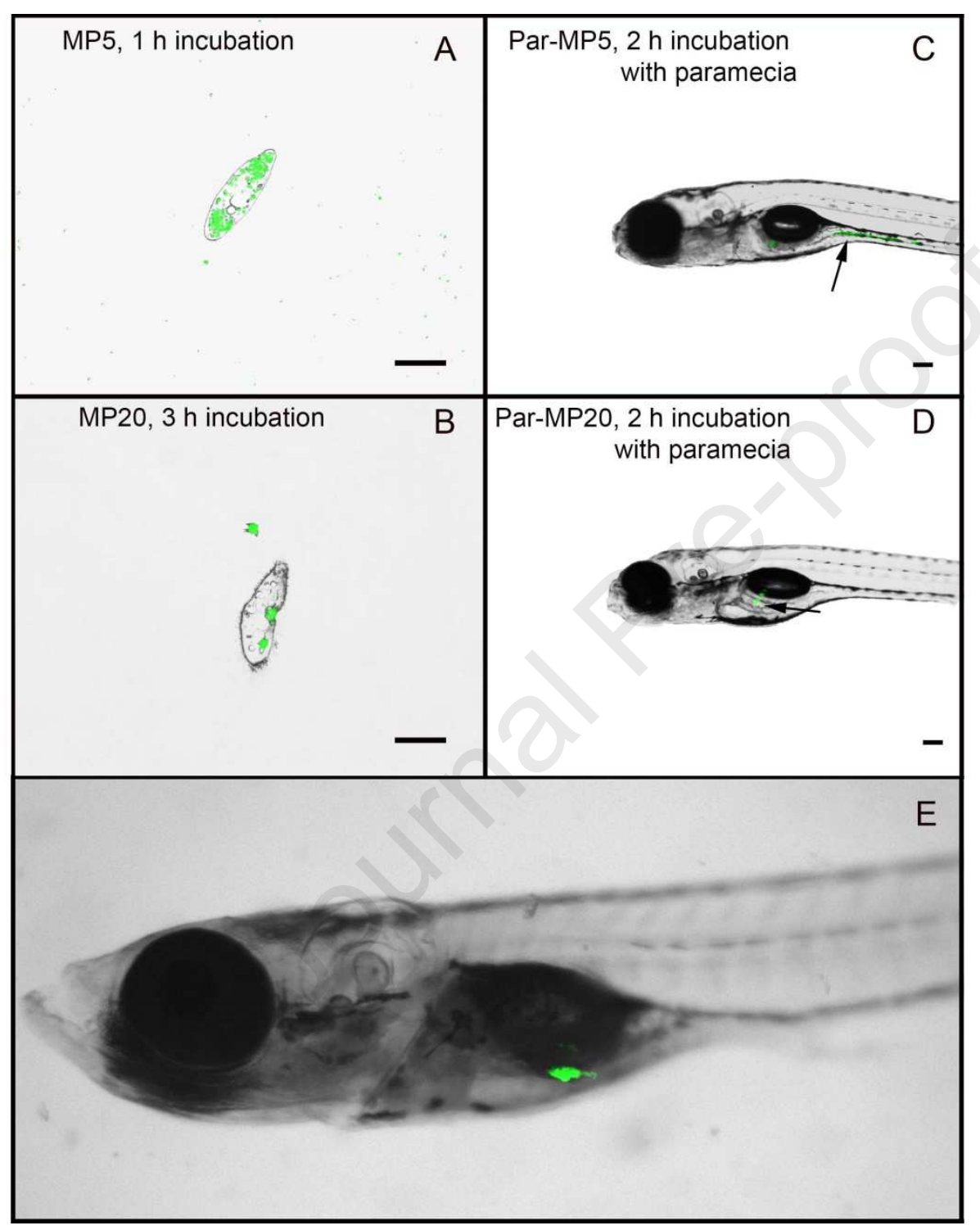

Fig. 1: Internalization of fluorescent MPs by Paramecium and transfer to zebrafish (Danio rerio) larvae. Detection of fluorescent MPs inside Paramecium after $1 \mathrm{~h}$ incubation with MP5 (A) and $3 \mathrm{~h}$ incubation with MP20 (B). Ingestion of fluorescent MPs by fish larvae fed Paramecium previously incubated with MPs for 2 hours: 168 hpf zebrafish larvae fed Par-MP5 (C) or Par-MP20 (D); 264 hpf marine medaka larvae fed Par-MP5 (E; green fluorescence overlaid with bright field image). Scale bars: $100 \mu \mathrm{m}$. 
To further characterize the trophic transfer, ingestion of particles by zebrafish larvae was monitored for different feeding durations ( $1-6 \mathrm{~h})$ and starting at different ages (96 - $192 \mathrm{hpf}$; Table 2). Independent of the feeding duration, transfer could only be documented from $\geq 120$ hpf. Starting at this age, fluorescence was readily detected in larvae. Furthermore, after $5 \mathrm{~h}$ feeding, one larva was observed egesting microplastic-containing feces. There were no MPs visible in intestinal tracts of larvae incubated with waterborne MPs, thus, larvae did not feed directly on MPs, only via intermediate prey at this age.

Table 2: Transfer of Paramecium loaded with small microplastic particles (Par-MP1) to zebrafish (Danio rerio) larvae after variable feeding duration and feeding starting at different ages. Numbers indicate fluorescent larvae versus total number of larvae analyzed (in brackets).

\begin{tabular}{|c|c|c|c|c|c|c|}
\hline \multicolumn{2}{|c|}{ Feeding start time } & $96 \mathrm{hpf}$ & $120 \mathrm{hpf}$ & $144 \mathrm{hpf}$ & $168 \mathrm{hpf}$ & $192 \mathrm{hpf}$ \\
\hline \multirow{9}{*}{ 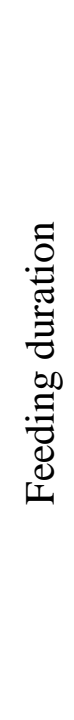 } & $1 \mathrm{~h}$ & - & $4(12)$ & & - & - \\
\hline & \multirow[t]{2}{*}{$2 \mathrm{~h}$} & $0(11)$ & $12(12)$ & $7(12)$ & $11(12)$ & $8(8)$ \\
\hline & & - & $9(12)$ & $5(12)$ & $10(11)$ & $3(12)$ \\
\hline & $3 \mathrm{~h}$ & - & $11(11)$ & $8(12)$ & $11(12)$ & $10(12)$ \\
\hline & \multirow[t]{2}{*}{$4 \mathrm{~h}$} & $0(11)$ & $12(12)$ & $8(12)$ & $12(12)$ & $9(11)$ \\
\hline & & & $11(12$ & $8(11)$ & $12(12)$ & $7(7)$ \\
\hline & \multirow[t]{2}{*}{$5 \mathrm{~h}$} & $0(11)$ & $10(12)$ & $12(12)$ & $12(12)$ & $12(12)$ \\
\hline & & & - & $7(12)$ & $11(12)$ & - \\
\hline & $6 \mathrm{~h}$ & $0(11)$ & $11(11)$ & $10(11)$ & $12(12)$ & - \\
\hline
\end{tabular}

Trophic transfer of microplastic particles from Artemia nauplii to fish larvae

As described previously (Batel et al., 2016), Artemia Instar II successfully ingested MPs both MP5 and MP20. Since the uptake of particles by Artemia nauplii only starts at Instar II stage (body size $\sim 200 \mu \mathrm{m}$ ), feeding of fish larvae could only be initiated when the mouth opening of the fish larvae was wide enough, i.e. at about $6 \mathrm{~d}$ post-hatch $(\sim 8 \mathrm{dpf}=192 \mathrm{hpf}$ for zebrafish and $\sim 17 \mathrm{dpf}$ for medaka. At this age, larvae readily ingest Artemia nauplii and MPs transfer was easily visible (Fig. 2). 


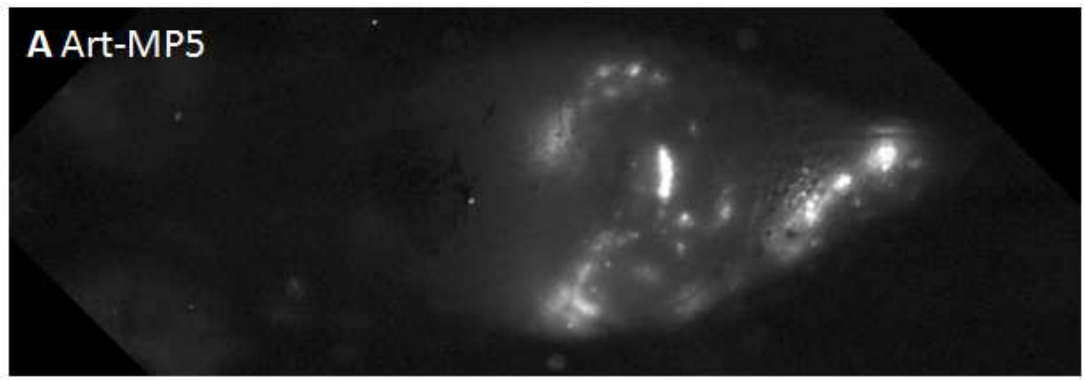

\section{B Art-MP20}

Fig. 2: Transfer of fluorescent MPs to marine medaka (Oryzias melastigma) larvae, dorsal view. Ingestion of fluorescent MPs by $17 \mathrm{dpf}$ medaka larvae fed Art-MP5 (A) Art-MP20 (B); ventral views. Note some autofluorescent pigment cells in B.

Independent from species and MPs size, the evolution of the proportion of fish larvae showing fluorescence followed the same pattern (Fig. 3) with an increase between days 1 and 2 and a significant decrease of the proportion of larvae showing fluorescence at day 3 (i.e. day 1 of clearance after the end of exposure to MP). At day 4 (day 2 of clearance), there were no larvae with fluorescence left anymore, independent of species and MP size.
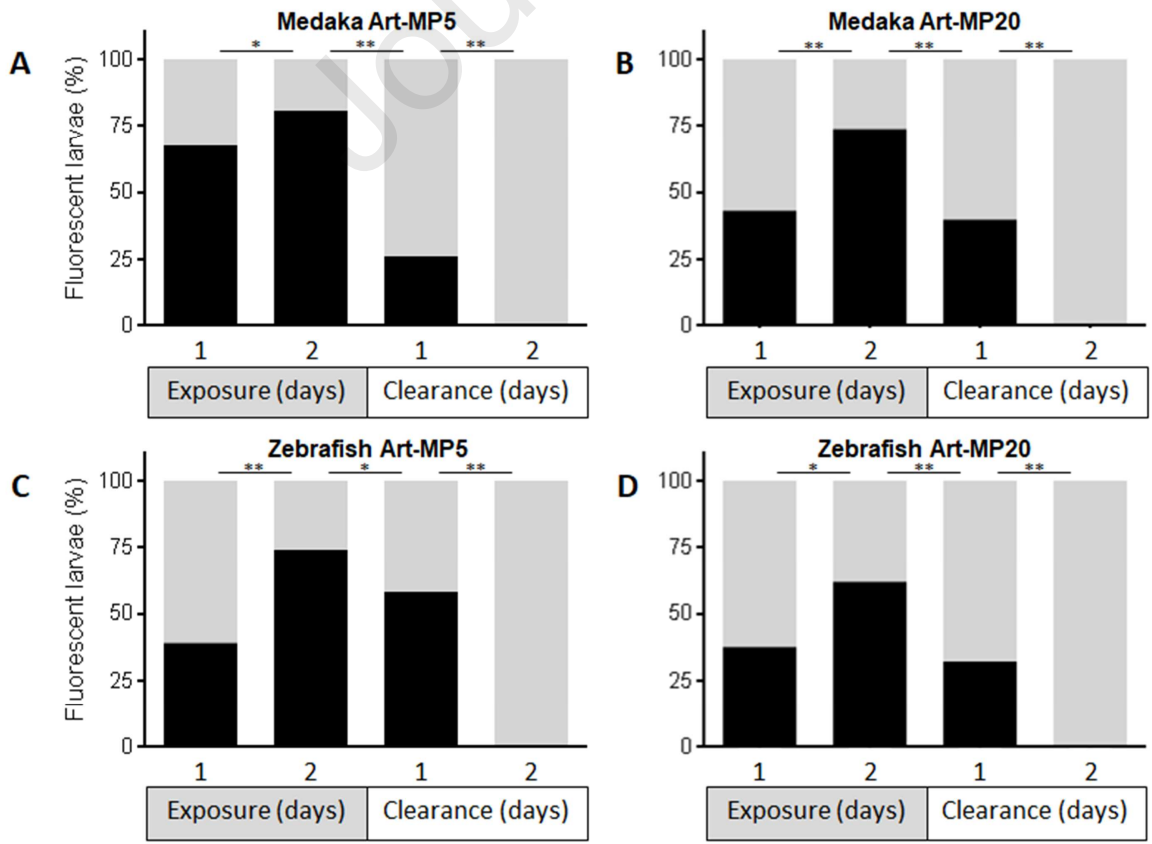

Fig. 3: Proportion of marine medaka (Oryzias melastigma) and zebrafish (Danio rerio) larvae showing fluorescence (MP uptake) over time after feeding with Artemia loaded with fluores- 
cent MPs. Fish larvae were fed on days 1 and 2 with Artemia that had been exposed to fluorescent MPs, followed by two additional days of clearance with non-exposed Artemia. Marine medaka larvae fed Art-MP5 (A) and Art-MP20 (B). Zebrafish larvae fed Art-MP5 (C) and Art-MP20 (D). Triplicates of 20 individuals were monitored; Differences between successive days have been tested using Fisher's exact test: $*=p<0.05 ; * *=p<0.01$.

In order to describe ingestion in both fish species in more detail, fluorescence intensity was analyzed within the gut lumen of fluorescent larvae (Fig. 4). The temporal pattern was very similar between species, but differed with MP size: In the case of Art-MP5, fluorescence was higher during feeding days without difference between days 1 and 2, if compared to day 1 of clearance. In contrast, in medaka fed Art-MP20, the fluorescence remained constant during the first 3 days, while in the case of zebrafish fluorescence was slightly lower on day 1 of clearance when compared to day 1 of exposure. In all cases, fluorescence had completely disappeared on day 2 of clearance. It is noteworthy that, independent of the species, the fluorescence intensity obtained with MP20 was significantly lower than with MP5.

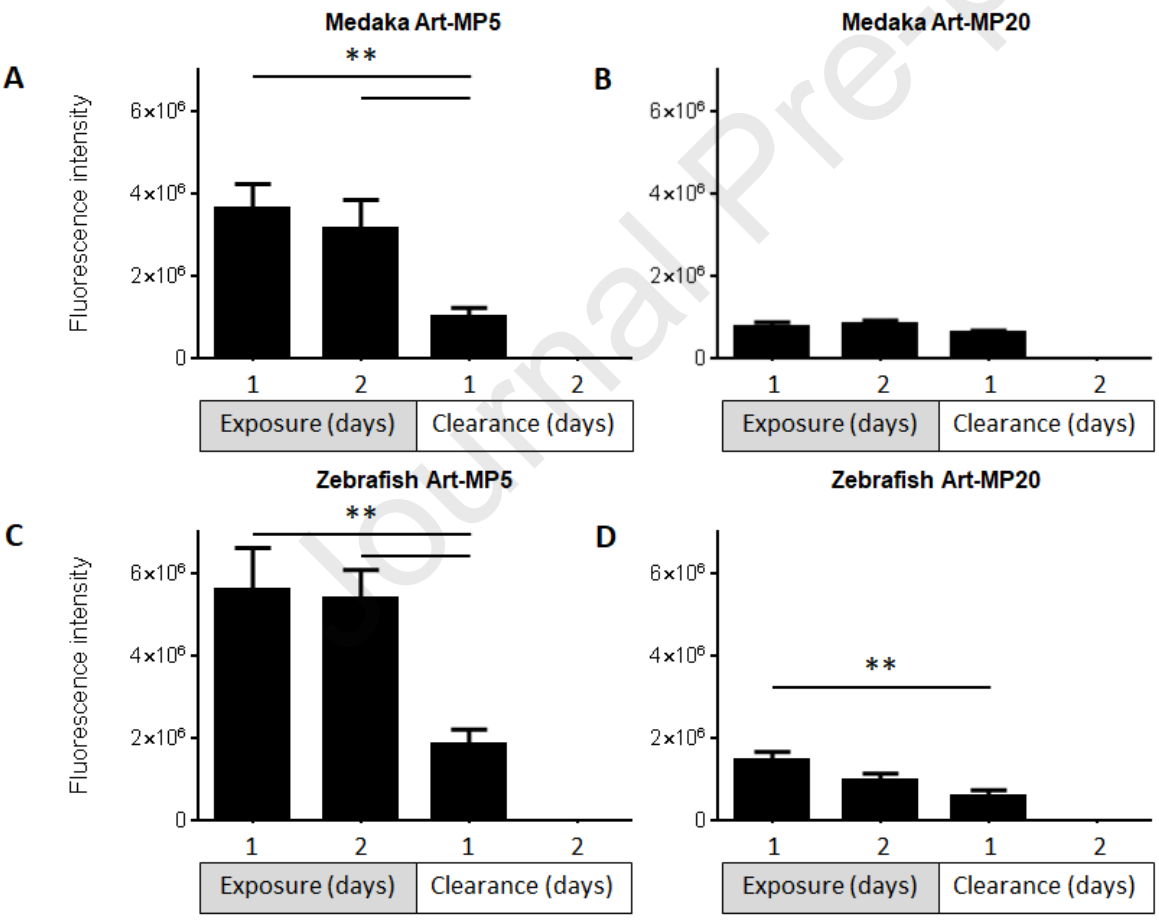

Fig. 4: Fluorescence intensity (MP uptake) in the gut lumen of zebrafish (Danio rerio) and marine medaka (Oryzias melastigma) measured in fluorescent larvae over time. Fish larvae were fed using the same schedule as described in Fig. 3. Marine medaka larvae were fed ArtMP5 (A) and Art-MP20 (B); zebrafish larvae were fed Art-MP5 (C) and Art-MP20 (D). Triplicates of 20 individuals were monitored; data are given as means \pm SEM; one-way-ANOVA: $* *=\mathrm{p}<0.01$. 


\section{Transfer of benzo[a]pyrene (BaP) to zebrafish and medaka larvae via MPs given to prey}

Due to its strong autofluorescence, BaP can easily be tracked within organisms. The BaPspecific fluorescence in fish larvae that had fed on Paramecium or Artemia nauplii previously loaded with BaP adsorbed to MPs thus confirmed successful transfer from MPs to fish larvae. Independent of particle size, no BaP-specific fluorescence was detected in larvae from either negative or desorption controls, or in larvae fed clean "virgin" MPs (Fig. 5).

The negative result for the desorption control specifically illustrates that in clean water BaP did not re-dissolve off the MPs into the water column. Therefore, BaP-specific fluorescence signals under other experimental conditions could not derive from previously desorbed $\mathrm{BaP}$ to water. Direct exposure to waterborne $\mathrm{BaP}$ (PC) also resulted in a distinct accumulation of $\mathrm{BaP}$ within fish larvae.

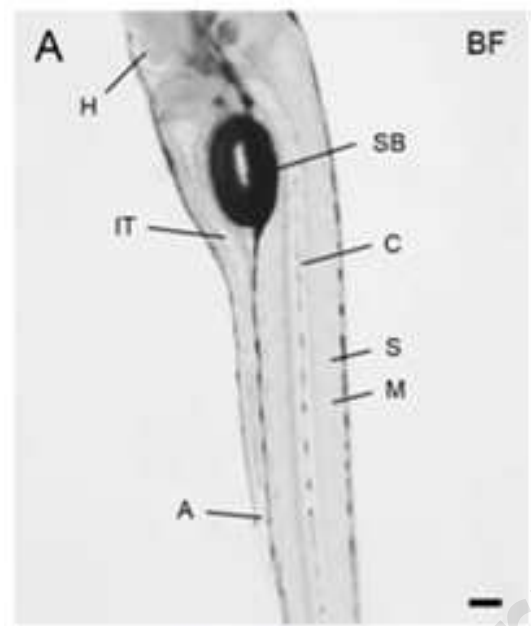

D

DC
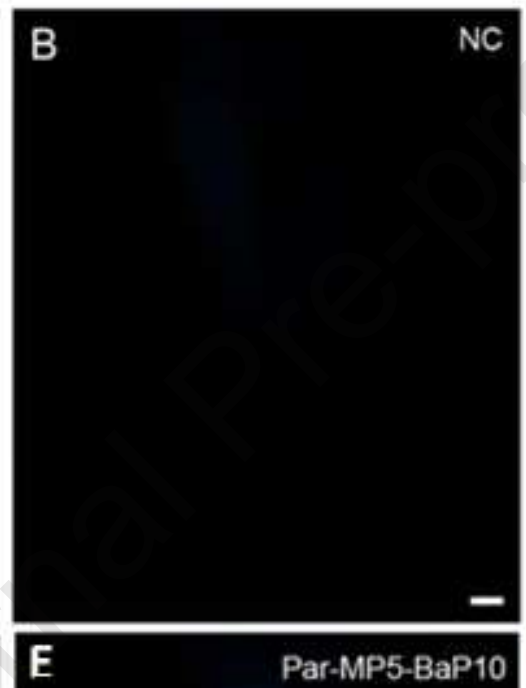
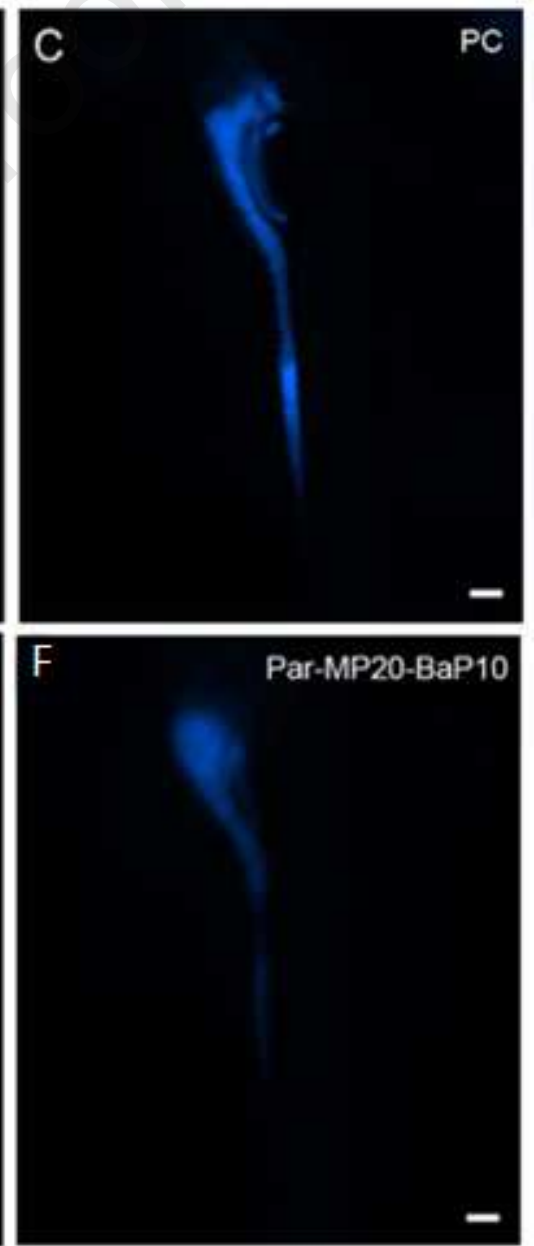

Par-MP20-BaP10

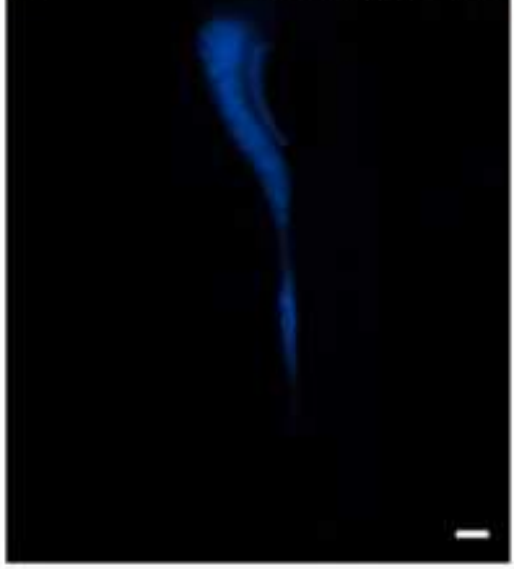

375 Fig. 5: Uptake of benzo[a]pyrene (BaP) into $168 \mathrm{~h}$ old zebrafish (Danio rerio) larvae after exposure to MP-BaP or feeding with Par-MP-BaP. (A) Bright field micrograph of the larvae ( $\mathrm{H}$ - heart, IT - intestinal tract, A - anus, SB - swim bladder, C - chorda, S - somites, M muscles). (B) Negative control without any fluorescence signal. (C) Positive control (100 nM waterborne $\mathrm{BaP}$ ) with a strong signal along the entire intestinal tract. (D) Desorption control (DC) without any fluorescence signal. (E) Larvae feeding on Par-MP5-BaP10 revealed a strong signal. (F) Larvae fed Par-MP20-BaP10. 


\section{Bioavailability of BaP transferred to fish larvae through MPs given via prey}

In order to biologically quantify the bioavailability of BaP transferred by MPs, the induction of cypla was monitored using qPCR in both species. In zebrafish, consistently with the absence of $\mathrm{BaP}$ fluorescence, no cypla induction was visible in negative controls and in fish fed on virgin MPs (independent of size), whereas a 90 fold induction could be documented for the positive control (waterborne BaP; Fig. 6A; $\mathrm{p}=0.035$ ). In the case of Par-MP5-BaP10, there was no significant induction of cypla, when compared to the negative control. In contrast, exposure to MP20-BaP10 significantly induced cypla transcription after exposure via Paramecium (Par-MP20-BaP10; fold change: 16.5, $\mathrm{p}=0.022$ ).

The same experiment was carried out using marine medaka and Artemia as live prey intermediate. After $2 \mathrm{~d}$ of exposure (i.e. 4 meals), no change of cypla transcription was observed in marine medaka larvae fed Art-MP5, if compared to the control (Artemia only; fold change: $1.455 ; \mathrm{p}=0.22$; Fig. 6B). Similarly, the use of Art-MP5-BaP100 produced no change of cypla transcription (fold change: $2.18 ; \mathrm{p}=0.17$ ). In contrast, when marine medaka were fed Art-MP5-BaP300, a significant induction of cypla transcription was observed, if compared to cypla transcription in Control larvae (fold change: 14.57 ; $=0.03$ ). These results demonstrated the efficiency of Artemia as an intermediate host to deliver MPs to fish larvae and the bioavailability of $\mathrm{BaP}$ after exposure to Art-MP5-BaP300.
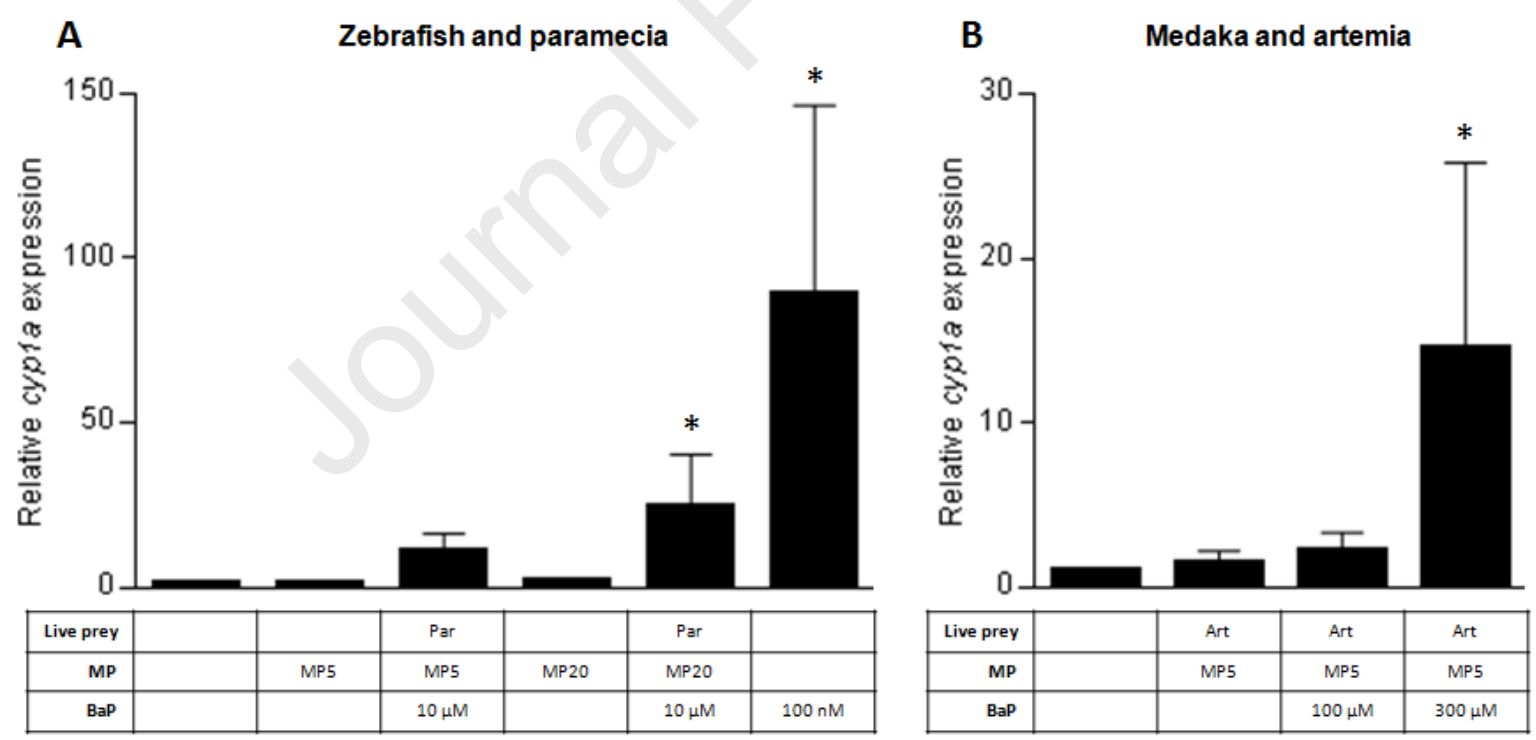

Fig. 6: Transcription of cypla relative to the negative control (NC; first bar of each graph) in zebrafish (Danio rerio; A) and marine medaka (Oryzias melastigma; B). Tables below each graph describe exposure conditions. Note that scales are different between graphs. Three (zebrafish) and six (medaka) pools of ten larvae were monitored; data are given as means \pm SD; statistical analyses based on ANOVA-on-ranks against NC: $*=p<0.05$. 


\section{Discussion}

409

410

411

412

413

414

415

416

417

418

419

420

421

422

423

424

425

426

427

428

429

430

431

432

433

434

435

436

437

438

439

440

441

442

443

444

445

446

447

The results of this study reveal the efficient transfer of very small MPs with dimensions in the lower $\mu \mathrm{m}$ size range via trophic transfer through exposed prey in the micro- or millimeter range organisms to vertebrate larvae, highlighting the importance of considering trophic food webs when analyzing microplastic exposure. Using two types of MPs different in both structure and size illustrates the variability of type- and size-dependent effects on organisms. In the present experiment, we used well-defined $10-20 \mu \mathrm{m}$ polyethylene particles as well as 1 $5 \mu \mathrm{m}$ particles made up of a Cospheric ${ }^{\mathrm{TM}}$ proprietary plastic; both sizes are likely to regularly occur in the environment.

As a common model organism for freshwater protozoans, Paramecium had readily ingested the very small $1-5 \mu \mathrm{m}$ MPs of as early as $1 \mathrm{~h}$ after initiation of the incubation. In contrast, larger particles $(10-20 \mu \mathrm{m})$ were apparently too large to be ingested efficiently. A similar size range for plastic ingestion by Paramecium was mentioned by Holm et al. (2013), who fed Paramecium with $1 \mu \mathrm{m}$ fluorescent polystyrene particles (Holm et al., 2013). As representatives of zooplankton filter feeders, Artemia nauplii also ingested both 1 - 5 and $10-20 \mu \mathrm{m}$ MPs at high amounts, which had already been demonstrated by (Batel et al., 2016).

In both medaka and zebrafish larvae feeding on Paramecium and Artemia nauplii containing MPs could be documented inside the gastrointestinal tract within few hours of ingestion. Some variability was observed in MPs uptake, especially in the case of exposure of zebrafish through Paramecium (e.g. at $144 \mathrm{hpf}$ in Table 2). This may be related to variation in larval activity level through development (Vignet et al., 2013). In addition, in zebrafish, feeding starts at $5 \mathrm{dpf}$ and is associated with an increase in gut function at this age (Sadler et al., 2013). It is thus likely that what is observed at $144 \mathrm{hpf}$ is due to inter-individual variability in developmental rate, potentially affecting these traits. Such transfer of MPs through prey has already been shown from mesozooplankton to macrozooplankton (Setala et al., 2014) as well as from mussels to crabs (Farrell and Nelson, 2013), but - to the best of our knowledge - not in fish larvae. Conversely, after direct exposure via water, no MPs were visible in the intestinal tracts of the larvae. Thus, fish larvae primarily ingested the small MPs via the prey, but not directly via the water column.

Trophic transfer of microplastics is also receiving increasing attention in microplastic field studies. Nelms et al. (2018) analyzed sub-samples of scat from captive seals (Halichoerus grypus) and whole guts of wild caught Atlantic mackerel (Scomber scombrus) the seals were fed on. Results indicate that 'trophic transfer represents an indirect, yet potentially major pathway of microplastic ingestion for any species whose feeding ecology involves the consumption of whole prey, including humans' (Nelms et al., 2018). Trophic transfer of MPs has also been documented in the field: Welden et al. (2018) analyzed microplastics contents in plaice (Pleuronectes plastessa), spider crab (Maja squinado) and ingested sand eels (Ammodytes tobianus) and found microplastics in ingested sand eels, directly proving microplastic trophic transfer in the wild (Welden et al., 2018). This has also been suggested for Mediterranean fish species (Savoca et al., 2019a; Savoca et al., 2019b). 
In the present laboratory study, focus was laid on the mode-of-action of microplastic trophic transfer in early life-stages of fish, analyzing time scales and kinetics of first MPs uptake and potential transfer of hazardous chemicals by MPs using benzo[a]pyrene (BaP) as a model PAH. Zebrafish were feeding on Paramecium on MPs from $120 \mathrm{hpf}$, whereas marine medaka started feeding on Paramecium immediately from hatching. In the case of the fish species studied here, approx. 6 - $7 \mathrm{~d}$ after hatching (i.e. $8 \mathrm{dpf}$ for zebrafish and $17 \mathrm{dpf}$ for marine medaka), larvae were able to switch to larger prey and started feeding on Artemia nauplii. As a consequence, as shown above, exposure of fish larvae to MPs via live prey was able to reach high levels of exposure. This is in agreement with field studies, which revealed MP uptake in larvae of various fish species (Steer et al., 2017). Previous work showed that, in the case of zebrafish, uptake of MPs through Artemia nauplii also occurred in juveniles or adults (Batel et al., 2016); thus, trophic food chains can deliver significant amounts of very small MPs from the first food uptake by early life-stages of fish until adulthood, meaning a whole life exposure to very small MPs through uptake via prey.

Despite massive uptake of MPs, adverse effects never became obvious in neither Paramecium and Artemia nauplii, nor fish larvae. A longer exposure may have resulted in biological effects. Likewise, neither accumulation nor translocation to tissues other than the gut could be observed over time. This is in line with previous experiments performed in juvenile seabass (Dicentrarchus labrax) fed with the same MPs as in the present study, however, contained in regular food pellets (Mazurais et al., 2015). This lack of effects is likely due to the fast egestion rate of fish larvae: Effective egestion started $5 \mathrm{~h}$ after the onset of exposure, and disappearance of fluorescence in the gastrointestinal tracts of the larvae was complete after less than two days after the last exposure. This corroborates observations in seabass exposed to pellets spiked with MPs (Mazurais et al., 2015), where translocation to tissues could also not be observed. Likewise, previous studies using similar trophic exposure of adult zebrafish, Japanese medaka (Oryzias latipes) and fathead minnow (Pimephales promelas) revealed no translocation to tissues (Batel et al., 2020; Batel et al., 2016; Elizalde-Velazquez et al., 2020; Zhu et al., 2020). However, there are also reports on translocation in fish, particularly to the liver, after experimental exposure (Bakir et al., 2016; Ding et al., 2018) and in fish collected in the field (Avio et al., 2015; Collard et al., 2017). Such discrepancies cannot be resolved easily, since there is no correlation of translocation with MP size, shape, material or duration in the case of experimental exposures (Avio et al., 2015; Bakir et al., 2016). In freshwater studies, however, a recent review on MP uptake and translocation in a multitude of species revealed that, at least partly, studies reporting translocation should be re-evaluated (Triebskorn et al., 2019).

Another most important aspect in MP research is the much-discussed issue of a potential transfer of hazardous organic chemicals to aquatic organisms upon MP uptake (Bakir et al., 2016; Koelmans et al., 2016; Lohmann, 2017). In the present study, the transfer of benzo[a]pyrene $(\mathrm{BaP})$, a model PAH, was analyzed: Using BaP-specific autofluorescence and cypla induction, absorption of $\mathrm{BaP}$ by larvae and, thus, bioavailability of $\mathrm{BaP}$ could clearly be documented. However, concentrations of both microplastics and BaP were beyond environmentally relevant concentrations and thus only document potential modes-of-action. Com- 
parison of cypla transcription induction by positive control and prey is quite impossible since actual exposure of larvae depends on the number of MPs ingested by the prey and the number of preys ingested by larvae.

MP ingestion by Paramecium and Artemia nauplii, and consequently by fish larvae, was higher with $5 \mu \mathrm{m}$ MPs than with the larger $20 \mu \mathrm{m}$ MPs. In contrast, this difference did not become apparent when $\mathrm{BaP}$ transfer and subsequent BaP-specific fluorescence in larvae was visualized by optical means. The induction of cypla was even higher with the larger $20 \mu \mathrm{m}$ MPs than with $5 \mu \mathrm{m}$ MPs, which was most likely related to a difference in chemical composition of MPs. According to the suppliers, the $20 \mu \mathrm{m}$ MP particles were made of polyethylene (PE), whereas the smaller $5 \mu \mathrm{m}$ particles were made of a non-disclosed polymer other than $\mathrm{PE}$, at least according to their melting temperatures. Interestingly, the desorption control, which analyzed the desorption of BaP from MPs in clean water, produced no fluorescence in larvae. This points out that not only trophic transfer, but also the type of plastic used as a vehicle and chemical equilibria need to be taken into consideration when assessing the risk of MPs in the aquatic environment.

Although there has been a critical discussion about testing "clean" laboratory animals and MPs spiked with hazardous organic chemicals with regard to chemical equilibrium (Lohmann, 2017), the present study illustrates that, in simple mode-of-action studies, the feeding of MPs via prey may increase (1) the amount of MPs taken up into intestinal tracts of fish larvae and (2) at least the uptake of hazardous organic chemicals. Thus, transfer of hazardous organic chemicals bound to MP along trophic food chains might play an important role in aquatic ecosystems with respect to MP toxicity and the transfer of hazardous organic chemicals. Furthermore, it is important to note that hazardous organic chemicals on MPs may reach chemical equilibrium in one area, but - following drift of MPs - may reach areas that had not been in touch with high concentrations of hazardous organic chemicals before, e.g. the deep sea or remote areas (Van Cauwenberghe et al., 2013). Thus, the chemical equilibrium to aquatic organisms in such remote areas is most likely different from that in the regions of MP origin and might well account for the transfer of hazardous organic chemicals to biota.

Fish larvae can be exposed to MPs by prey from the very first day of feeding until adulthood, making exposure potentially lasting a whole life. Already at small scale, the transfer along food webs is most important in aquatic ecosystems. If MP transfer already starts at such small-scale events and continues to higher levels within trophic food webs, the overall livelong MP exposure in natural environments might well be higher than expected (Pannetier et al., 2020). This seems especially true regarding nanoplastic particles, for which the actual number is potentially by orders of magnitude higher than that of microplastics, and the biological importance is likely to be much higher than that of microplastics (Ivleva et al., 2017).

\section{Acknowledgments}

We are very thankful to Kada Boukerma (Ifremer-LDCM) for the FT-IR analyses and Lucette Joassard (Ifremer-LRHLR) for the qPCR analyses. The second author (ABa) is grateful for a 
grant by the National Scholarship Foundation of the German People (Studienstiftung des Deutschen Volkes) and $\mathrm{ABr}$ received an MSc grant from Ifremer. This work was supported by the Joint Programming Initiative Healthy and Productive Seas and Oceans (JPI Oceans) project EPHEMARE ("Ecotoxicological effects of microplastics in marine ecosystems") under funding by the German Federal Ministry for Science and Research (BMBF) under contract no. 03F0735A and the French National Research Agency (Agence National de La Recherche) under contract no. ANR-15-JOCE-0002-05. Additional funding was received from the German Federal Ministry for Science and Research under contract no. 02WRS1378J for the joint project MiWa ("Microplastics in the Water Cycle - Sampling, Specimen Treatment, Chemical Analyses, Distribution, Removal and Risk Assessment") within the scope of the RiSKWa ("Risk Management of Novel Contaminants and Pathogens in the Water Circle") program.

\section{References}

Alimba, C.G., Faggio, C., 2019. Microplastics in the marine environment: Current trends in environmental pollution and mechanisms of toxicological profile. Environ Toxicol Pharmacol 68, 6174.

Ashton, K., Holmes, L., Turner, A., 2010. Association of metals with plastic production pellets in the marine environment. Mar Pollut Bull 60, 2050-2055.

Au, S.Y., Lee, C.M., Weinstein, J.E., van den Hurk, P., Klaine, S.J., 2017. Trophic transfer of microplastics in aquatic ecosystems: Identifying critical research needs. Integr Environ Assess Manag 13, 505-509.

Avio, C.G., Gorbi, S., Milan, M., Benedetti, M., Fattorini, D., d'Errico, G., Pauletto, M., Bargelloni, L., Regoli, F., 2015. Pollutants bioavailability and toxicological risk from microplastics to marine mussels. Environ Pollut 198, 211-222.

Bakir, A., O'Connor, I.A., Rowland, S.J., Hendriks, A.J., Thompson, R.C., 2016. Relative importance of microplastics as a pathway for the transfer of hydrophobic organic chemicals to marine life. Environ Pollut 219, 56-65.

Bakir, A., Rowland, S.J., Thompson, R.C., 2012. Competitive sorption of persistent organic pollutants onto microplastics in the marine environment. Mar Pollut Bull 64, 2782-2789.

Batel, A., Baumann, L., Carteny, C.C., Cormier, B., Keiter, S.H., Braunbeck, T., 2020. Histological, enzymatic and chemical analyses of the potential effects of differently sized microplastic particles upon long-term ingestion in zebrafish (Danio rerio). Mar Pollut Bull 153, 111022.

Batel, A., Borchert, F., Reinwald, H., Erdinger, L., Braunbeck, T., 2018. Microplastic accumulation patterns and transfer of benzo[a]pyrene to adult zebrafish (Danio rerio) gills and zebrafish embryos. Environmental Pollution 235, 918-930.

Batel, A., Linti, F., Scherer, M., Erdinger, L., Braunbeck, T., 2016. The transfer of benzo[a]pyrene from microplastics to Artemia nauplii and further to zebrafish via a trophic food web experiment CYP1A induction and visual tracking of persistent organic pollutants. Environ Toxicol Chem.

Beck, M.W., Heck, K.L., Able, K.W., Childers, D.L., Eggleston, D.B., Gillanders, B.M., Halpern, B., Hays, C.G., Hoshino, K., Minello, T.J., Orth, R.J., Sheridan, P.F., Weinstein, M.P., 2001. The Identification, Conservation, and Management of Estuarine and Marine Nurseries for Fish and Invertebrates. BioScience 51, 633-641.

Beiras, R., Bellas, J., Cachot, J., Cormier, B., Cousin, X., Engwall, M., Gambardella, C., Garaventa, F., Keiter, S., Le Bihanic, F., Lopez-Ibanez, S., Piazza, V., Rial, D., Tato, T., Vidal-Linan, L., 2018. Ingestion and contact with polyethylene microplastics does not cause acute toxicity on marine zooplankton. J Hazard Mater 360, 452-460. 
Besseling, E., Foekema, E.M., van den Heuvel-Greve, M.J., Koelmans, A.A., 2017. The Effect of Microplastic on the Uptake of Chemicals by the Lugworm Arenicola marina (L.) under Environmentally Relevant Exposure Conditions. Environ Sci Technol 51, 8795-8804.

Browne, M.A., Crump, P., Niven, S.J., Teuten, E., Tonkin, A., Galloway, T., Thompson, R., 2011. Accumulation of microplastic on shorelines woldwide: sources and sinks. Environ Sci Technol 45, 9175-9179.

Cole, M., Lindeque, P., Fileman, E., Halsband, C., Goodhead, R., Moger, J., Galloway, T.S., 2013. Microplastic ingestion by zooplankton. Environ Sci Technol 47, 6646-6655.

Collard, F., Gilbert, B., Compere, P., Eppe, G., Das, K., Jauniaux, T., Parmentier, E., 2017. Microplastics in livers of European anchovies (Engraulis encrasicolus, L.). Environ Pollut 229, 10001005.

Cormier, B., Batel, A., Cachot, J., Bégout, M.-L., Braunbeck, T., Cousin, X., Keiter, S.H., 2019. Multi-Laboratory Hazard Assessment of Contaminated Microplastic Particles by Means of Enhanced Fish Embryo Test With the Zebrafish (Danio rerio). Frontiers in Environmental Science 7.

Desforges, J.P., Galbraith, M., Ross, P.S., 2015. Ingestion of Microplastics by Zooplankton in the Northeast Pacific Ocean. Arch Environ Contam Toxicol 69, 320-330.

Devriese, L.I., De Witte, B., Vethaak, A.D., Hostens, K., Leslie, H.A., 2017. Bioaccumulation of PCBs from microplastics in Norway lobster (Nephrops norvegicus): An experimental study. Chemosphere 186, 10-16.

Diepens, N.J., Koelmans, A.A., 2018. Accumulation of Plastic Debris and Associated Contaminants in Aquatic Food Webs. Environ Sci Technol 52, 8510-8520.

Ding, J., Zhang, S., Razanajatovo, R.M., Zou, H., Zhu, W., 2018. Accumulation, tissue distribution, and biochemical effects of polystyrene microplastics in the freshwater fish red tilapia (Oreochromis niloticus). Environ Pollut 238, 1-9.

Eerkes-Medrano, D., Thompson, R.C., Aldridge, D.C., 2015. Microplastics in freshwater systems: A review of the emerging threats, identification of knowledge gaps and prioritisation of research needs. Water Res 75, 63-82.

Elizalde-Velazquez, A., Carcano, A.M., Crago, J., Green, M.J., Shah, S.A., Canas-Carrell, J.E., 2020. Translocation, trophic transfer, accumulation and depuration of polystyrene microplastics in Daphnia magna and Pimephales promelas. Environ Pollut 259, 113937.

Endo, S., Takizawa, R., Okuda, K., Takada, H., Chiba, K., Kanehiro, H., Ogi, H., Yamashita, R., Date, T., 2005. Concentration of polychlorinated biphenyls (PCBs) in beached resin pellets: variability among individual particles and regional differences. Mar Pollut Bull 50, 1103-1114.

Eriksen, M., Lebreton, L.C., Carson, H.S., Thiel, M., Moore, C.J., Borerro, J.C., Galgani, F., Ryan, P.G., Reisser, J., 2014. Plastic Pollution in the World's Oceans: More than 5 Trillion Plastic Pieces Weighing over 250,000 Tons Afloat at Sea. PLoS One 9, e111913.

Farrell, P., Nelson, K., 2013. Trophic level transfer of microplastic: Mytilus edulis (L.) to Carcinus maenas (L.). Environ Pollut 177, 1-3.

Fisner, M., Taniguchi, S., Moreira, F., Bicego, M.C., Turra, A., 2013. Polycyclic aromatic hydrocarbons (PAHs) in plastic pellets: variability in the concentration and composition at different sediment depths in a sandy beach. Mar Pollut Bull 70, 219-226.

Gassel, M., Rochman, C.M., 2019. The complex issue of chemicals and microplastic pollution: A case study in North Pacific lanternfish. Environ Pollut 248, 1000-1009.

Gove, J.M., Whitney, J.L., McManus, M.A., Lecky, J., Carvalho, F.C., Lynch, J.M., Li, J., Neubauer, P., Smith, K.A., Phipps, J.E., Kobayashi, D.R., Balagso, K.B., Contreras, E.A., Manuel, M.E., Merrifield, M.A., Polovina, J.J., Asner, G.P., Maynard, J.A., Williams, G.J., 2019. Prey-size plastics are invading larval fish nurseries. Proceedings of the National Academy of Sciences 116, 24143.

Guzzetti, E., Sureda, A., Tejada, S., Faggio, C., 2018. Microplastic in marine organism: Environmental and toxicological effects. Environ Toxicol Pharmacol 64, 164-171.

Heinrich, P., Hanslik, L., Kammer, N., Braunbeck, T., 2020. The tox is in the detail: technical fundamentals for designing, performing, and interpreting experiments on toxicity of microplastics and associated substances. Environ Sci Pollut Res Int. 27, 22292-22318. 
Hermabessiere, L., Dehaut, A., Paul-Pont, I., Lacroix, C., Jezequel, R., Soudant, P., Duflos, G., 2017. Occurrence and effects of plastic additives on marine environments and organisms: A review. Chemosphere 182, 781-793.

Hermsen, E., Pompe, R., Besseling, E., Koelmans, A.A., 2017. Detection of low numbers of microplastics in North Sea fish using strict quality assurance criteria. Mar Pollut Bull 122, 253-258.

Holm, P., Schulz, G., Athanasopulu, K., 2013. Mikroplastik - ein unsichtbarer Störenfried. Biologie in unserer Zeit 43, 27-33.

ISO, 1996. ISO 7346-3 -- Water quality -- Determination of the acute lethal toxicity of substances to a freshwater fish [Brachydanio rerio Hamilton-Buchanan (Teleostei, Cyprinidae)] -- Part 3: Flowthrough method.

Ivleva, N.P., Wiesheu, A.C., Niessner, R., 2017. Microplastic in Aquatic Ecosystems. Angewandte Chemie International Edition 56, 1720-1739.

Jovanovic, B., 2017. Ingestion of microplastics by fish and its potential consequences from a physical perspective. Integr Environ Assess Manag 13, 510-515.

Karami, A., Groman, D.B., Wilson, S.P., Ismail, P., Neela, V.K., 2017. Biomarker responses in zebrafish (Danio rerio) larvae exposed to pristine low-density polyethylene fragments. Environ Pollut 223, 466-475.

Koelmans, A.A., Bakir, A., Burton, G.A., Janssen, C.R., 2016. Microplastic as a Vector for Chemicals in the Aquatic Environment: Critical Review and Model-Supported Reinterpretation of Empirical Studies. Environ Sci Technol 50, 3315-3326.

Lammer, E., Carr, G.J., Wendler, K., Rawlings, J.M., Belanger, S.E., Braunbeck, T., 2009. Is the fish embryo toxicity test (FET) with the zebrafish (Danio rerio) a potential alternative for the fish acute toxicity test? Comparative Biochemistry and Physiology Part C: Toxicology \& Pharmacology 149, 196-209.

Le Bihanic, F., Clerandeau, C., Cormier, B., Crebassa, J.C., Keiter, S.H., Beiras, R., Morin, B., Begout, M.L., Cousin, X., Cachot, J., 2020. Organic contaminants sorbed to microplastics affect marine medaka fish early life stages development. Mar Pollut Bull 154, 111059.

Lim, L.C., Dhert, P., Sorgeloos, P., 2003. Recent developments in the application of live feeds in the freshwater ornamental fish culture. Aquaculture (Amsterdam, Netherlands) 227, 319-331.

Lohmann, R., 2017. Microplastics are not important for the cycling and bioaccumulation of organic pollutants in the oceans-but should microplastics be considered POPs themselves? Integrated Environmental Assessment and Management 13, 460-465.

Ma, Q., Lu, A.Y., 2007. CYP1A induction and human risk assessment: an evolving tale of in vitro and in vivo studies. Drug Metab Dispos 35, 1009-1016.

Mato, Y., Isobe, T., Takada, H., Kanehiro, H., Ohtake, C., Kaminuma, T., 2001. Plastic resin pellets as a transport medium for toxic chemicals in the marine environment. Environ Sci Technol 35, 318-324.

Mazurais, D., Ernande, B., Quazuguel, P., Severe, A., Huelvan, C., Madec, L., Mouchel, O., Soudant, P., Robbens, J., Huvet, A., Zambonino-Infante, J., 2015. Evaluation of the impact of polyethylene microbeads ingestion in European sea bass (Dicentrarchus labrax) larvae. Mar Environ Res 112, 78-85.

Nelms, S.E., Galloway, T.S., Godley, B.J., Jarvis, D.S., Lindeque, P.K., 2018. Investigating microplastic trophic transfer in marine top predators. Environmental Pollution 238, 999-1007.

Ogata, Y., Takada, H., Mizukawa, K., Hirai, H., Iwasa, S., Endo, S., Mato, Y., Saha, M., Okuda, K., Nakashima, A., Murakami, M., Zurcher, N., Booyatumanondo, R., Zakaria, M.P., Dung le, Q., Gordon, M., Miguez, C., Suzuki, S., Moore, C., Karapanagioti, H.K., Weerts, S., McClurg, T., Burres, E., Smith, W., Van Velkenburg, M., Lang, J.S., Lang, R.C., Laursen, D., Danner, B., Stewardson, N., Thompson, R.C., 2009. International Pellet Watch: global monitoring of persistent organic pollutants (POPs) in coastal waters. 1. Initial phase data on PCBs, DDTs, and HCHs. Mar Pollut Bull 58, 14371446.

Pannetier, P., Morin, B., Le Bihanic, F., Dubreil, L., Clerandeau, C., Chouvellon, F., Van Arkel, K., Danion, M., Cachot, J., 2020. Environmental samples of microplastics induce significant toxic effects in fish larvae. Environ Int 134, 105047.

Pfaffl, M.W., 2001. A new mathematical model for relative quantification in real-time RT-PCR. Nucleic Acids Res 29, e45. 
Pfaffl, M.W., Horgan, G.W., Dempfle, L., 2002. Relative expression software tool (REST@) for group-wise comparison and statistical analysis of relative expression results in real-time PCR. Nucleic Acids Research 30, e36-e36.

Pfaffl, M.W., Tichopad, A., Prgomet, C., Neuvians, T.P., 2004. Determination of stable housekeeping genes, differentially regulated target genes and sample integrity: BestKeeper--Excelbased tool using pair-wise correlations. Biotechnology letters 26, 509-515.

Porazinski, S.R., Wang, H., Furutani-Seiki, M., 2010. Microinjection of medaka embryos for use as a model genetic organism. Journal of visualized experiments : JoVE. URL: https://www.jove.com/video/1937, DOI: doi:10.3791/1937

Rios, L.M., Moore, C., Jones, P.R., 2007. Persistent organic pollutants carried by synthetic polymers in the ocean environment. Mar Pollut Bull 54, 1230-1237.

Rochman, C.M., Hoh, E., Kurobe, T., Teh, S.J., 2013. Ingested plastic transfers hazardous chemicals to fish and induces hepatic stress. Sci Rep 3, 3263.

Rummel, C.D., Loder, M.G., Fricke, N.F., Lang, T., Griebeler, E.M., Janke, M., Gerdts, G., 2016. Plastic ingestion by pelagic and demersal fish from the North Sea and Baltic Sea. Mar Pollut Bull 102, 134-141.

Sadler, K.C., Rawls, J.F., Farber, S.A., 2013. Getting the inside tract: new frontiers in zebrafish digestive system biology. Zebrafish 10, 129-131.

Savoca, S., Capillo, G., Mancuso, M., Bottari, T., Crupi, R., Branca, C., Romano, V., Faggio, C., D'Angelo, G., Spanò, N., 2019a. Microplastics occurrence in the Tyrrhenian waters and in the gastrointestinal tract of two congener species of seabreams. Environ Toxicol Pharmacol 67, 35-41.

Savoca, S., Capillo, G., Mancuso, M., Faggio, C., Panarello, G., Crupi, R., Bonsignore, M., D'Urso, L., Compagnini, G., Neri, F., Fazio, E., Romeo, T., Bottari, T., Spanò, N., 2019b. Detection of artificial cellulose microfibers in Boops boops from the northern coasts of Sicily (Central Mediterranean). Sci Total Environ 691, 455-465.

Schneider, C.A., Rasband, W.S., Eliceiri, K.W., 2012. NIH Image to ImageJ: 25 years of image analysis. Nat Meth 9, 671-675.

Scopetani, C., Cincinelli, A., Martellini, T., Lombardini, E., Ciofini, A., Fortunati, A., Pasquali, V., Ciattini, S., Ugolini, A., 2018. Ingested microplastic as a two-way transporter for PBDEs in Talitrus saltator. Environ Res 167, 411-417.

Setala, O., Fleming-Lehtinen, V., Lehtiniemi, M., 2014. Ingestion and transfer of microplastics in the planktonic food web. Environ Pollut 185, 77-83.

Sleight, V.A., Bakir, A., Thompson, R.C., Henry, T.B., 2017. Assessment of microplastic-sorbed contaminant bioavailability through analysis of biomarker gene expression in larval zebrafish. Mar Pollut Bull 116, 291-297.

Steer, M., Cole, M., Thompson, R.C., Lindeque, P.K., 2017. Microplastic ingestion in fish larvae in the western English Channel. Environ Pollut 226, 250-259.

Strungaru, S.-A., Jijie, R., Nicoara, M., Plavan, G., Faggio, C., 2019. Micro- (nano) plastics in freshwater ecosystems: Abundance, toxicological impact and quantification methodology. TrAC Trends in Analytical Chemistry 110, 116-128.

Teuten, E.L., Saquing, J.M., Knappe, D.R., Barlaz, M.A., Jonsson, S., Bjorn, A., Rowland, S.J., Thompson, R.C., Galloway, T.S., Yamashita, R., Ochi, D., Watanuki, Y., Moore, C., Viet, P.H., Tana, T.S., Prudente, M., Boonyatumanond, R., Zakaria, M.P., Akkhavong, K., Ogata, Y., Hirai, H., Iwasa, S., Mizukawa, K., Hagino, Y., Imamura, A., Saha, M., Takada, H., 2009. Transport and release of chemicals from plastics to the environment and to wildlife. Philos Trans R Soc Lond B Biol Sci 364, 2027-2045.

Thompson, R.C., Olsen, Y., Mitchell, R.P., Davis, A., Rowland, S.J., John, A.W., McGonigle, D., Russell, A.E., 2004. Lost at sea: where is all the plastic? Science 304, 838.

Triebskorn, R., Braunbeck, T., Grummt, T., Hanslik, L., Huppertsberg, S., Jekel, M., Knepper, T.P., Krais, S., Müller, Y.K., Pittroff, M., Ruhl, A.S., Schmieg, H., Schür, C., Strobel, C., Wagner, M., Zumbülte, N., Köhler, H.-R., 2019. Relevance of nano- and microplastics for freshwater ecosystems: A critical review. TrAC Trends in Analytical Chemistry 110, 375-392.

Van Cauwenberghe, L., Devriese, L., Galgani, F., Robbens, J., Janssen, C.R., 2015. Microplastics in sediments: A review of techniques, occurrence and effects. Mar Environ Res 111, 5-17. 
Van Cauwenberghe, L., Vanreusel, A., Mees, J., Janssen, C.R., 2013. Microplastic pollution in deep-sea sediments. Environ Pollut 182, 495-499.

van der Hal, N., Yeruham, E., Shukis, D., Rilov, G., Astrahan, P., Angel, D.L., 2020. Uptake and incorporation of PCBs by eastern Mediterranean rabbitfish that consumed microplastics. Mar Pollut Bull 150, 110697.

Velzeboer, I., Kwadijk, C.J., Koelmans, A.A., 2014. Strong sorption of PCBs to nanoplastics, microplastics, carbon nanotubes, and fullerenes. Environ Sci Technol 48, 4869-4876.

Vignet, C., Begout, M.L., Pean, S., Lyphout, L., Leguay, D., Cousin, X., 2013. Systematic screening of behavioral responses in two zebrafish strains. Zebrafish 10, 365-375.

von Moos, N., Burkhardt-Holm, P., Köhler, A., 2012. Uptake and Effects of Microplastics on Cells and Tissue of the Blue Mussel Mytilus edulis L. after an Experimental Exposure. Environmental Science \& Technology 46, 11327-11335.

Wardrop, P., Shimeta, J., Nugegoda, D., Morrison, P.D., Miranda, A., Tang, M., Clarke, B.O., 2016. Chemical Pollutants Sorbed to Ingested Microbeads from Personal Care Products Accumulate in Fish. Environ Sci Technol 50, 4037-4044.

Watts, A.J., Urbina, M.A., Corr, S., Lewis, C., Galloway, T.S., 2015. Ingestion of Plastic Microfibers by the Crab Carcinus maenas and Its Effect on Food Consumption and Energy Balance. Environ Sci Technol 49, 14597-14604.

Welden, N.A., Abylkhani, B., Howarth, L.M., 2018. The effects of trophic transfer and environmental factors on microplastic uptake by plaice, Pleuronectes plastessa, and spider crab, Maja squinado. Environmental Pollution 239, 351-358.

Wright, S.L., Rowe, D., Thompson, R.C., Galloway, T.S., 2013. Microplastic ingestion decreases energy reserves in marine worms. Curr Biol 23, R1031-1033.

Zhu, M., Chernick, M., Rittschof, D., Hinton, D.E., 2020. Chronic dietary exposure to polystyrene 764 microplastics in maturing Japanese medaka (Oryzias latipes). Aquatic Toxicology 220, 105396. 
Highlights

- Microplastics are readily ingested by unicellular or planktonic organisms

- Microplastics are efficiently delivered to fish larvae from these organisms

- Benzo[a]pyrene sorbed on microplastics is transferred from prey to fish larvae 


\section{Declaration of interests}

$\bigotimes$ The authors declare that they have no known competing financial interests or personal relationships that could have appeared to influence the work reported in this paper.

$\square$ The authors declare the following financial interests/personal relationships which may be considered as potential competing interests: 